\title{
Hacia una tendencia modernista (simbolista): el drama Desolación (1917) de Enrique López Albújar
}

\author{
Williams Nicks Ventura Vásquez \\ Universidad Nacional Mayor de San Marcos
}

\section{Resumen}

Estudia la influencia del modernismo - que produjo una reforma en la literatura hispanoamericana - en el teatro peruano con el drama Desolación (1917) de Enrique López Albújar, el cual manifiesta rasgos de la normativa decimonónica del siglo XIX, empero busca nuevos parámetros de representación, un nuevo contenido temático y una calidad artística en el lenguaje para determinar el efecto del modernismo, bajo la modalidad simbolista, en el teatro peruano. Examina esta tendencia literaria y analiza esta pieza teatral desde una visión semiológica y rítmica. El estudio aporta a las diversas investigaciones sobre el modernismo que permitió la renovación artística en la poesía y la narrativa y que sobre la creación teatral estaban ausentes.

Palabras clave: Modernismo, Teatro peruano, Enrique López Albújar, Desolación, Semiología del teatro, Rítmica

\begin{abstract}
He studied the influence of modernism — which produced a reform in Spanish-American literature- in the Peruvian theatre with the drama Desolation (1917) by Enrique López Albújar, which manifests features of the nineteenth norms of the nineteenth century, but looks for new Parameters of representation, a new thematic content and an artistic quality in the language to determine the effect of modernism, under the Symbolist modality, in the Peruvian theatre. $\mathrm{He}$ examines this literary trend and analyses this theatrical piece from a semiotic and rhythmic view. The study contributes to the diverse researches on the modernism that allowed the artistic renewal in the poetry and the narrative and that on the theatrical creation were absent.
\end{abstract}

Keywords: Modernism, Peruvian Theatre, Enrique López Albújar, Desolation, Semiology of theatre, Rhythmic 


\section{Hacia una tendencia modernista (simbolista): el drama Desolación (1917) de Enrique López Albújar}

\section{Introducción}

Las indagaciones respecto a la influencia del modernismo en las piezas teatrales peruanas son escasas. A diferencia de la enorme cantidad de estudios sobre los demás géneros literarios, existen pocas investigaciones loables en torno al teatro que, lamentablemente, no lograron motivar a la crítica especializada. Es decir, hay poco interés al género teatral y más en comprender la presencia o el aporte del modernismo en una composición dramática. Intentaremos esclarecer este ámbito casi desconocido mediante el análisis de Desolación (1917) de Enrique López Albújar (1872-1966).

\section{E1 modernismo en el Perú}

Iván Schulman, en El modernismo hispanoamericano (1969), expone una visión multifacética del fenómeno modernista debido a su naturaleza ideológica en todos los ámbitos socioculturales, considerándolo una renovación ideológica, social y política, donde "las instituciones y actividades humanas, inclusive las literarias, pasaban por un período de reajuste” (p. 16).

Según Schulman, el modernismo no se reduce a un arte decorativo y exótico, preciosista y afrancesada, sino a un estilo en constante conflicto motivado por la libertad creadora y la búsqueda de una estética original. Esto produjo diversas posiciones innovadoras y antitéticas, "una estética multifacética y contradictoria", en un período de "florecimiento modernista". Así, convergen "un tardío romanticismo, el naturalismo, el parnasianismo, el simbolismo, el impresionismo y el expresionismo" (p. 23), siendo la única particularidad estilística el rechazo a las formas académicas; es decir, el fenómeno modernista se caracteriza por las contradicciones y evoluciones de diversas poéticas.

En consonancia con la visión de Schulman, resulta valioso el aporte de Washington Delgado quien, en Historia de la literatura republicana (1984), determina 
que el modernismo peruano apareció tardíamente por la poca capacidad de creación, lo que conllevó a no formar "una escuela o movimiento definido y unificado" (p. 96).

Para Delgado, el modernismo peruano se compone en tres etapas: 1) "el modernismo inicial”, supeditado por la personalidad y el verbo sonoro de Chocano, sin la expresión poética de la lírica rubendariana y con el raigambre romántico y neoclásico (p. 96); 2) "la plenitud del modernismo", con la vertiente arielista, arraigado al refinamiento poético de Darío, la ideología de Rodó y la prédica revolucionaria de Manuel González Prada (p. 98); y la vertiente de los colónidas, liderado por Valdelomar, quienes regresaron a los cimientos creativos del modernismo como el gusto por la imagen sonora y colorista, la exploración formal, la contraposición académica y el acercamiento a las provincias (p. 102); y 3) "la evolución última", con dos tendencias opuestas: el vínculo con la realidad, los sucesos provincianos y familiares, y la interiorización, el ensueño y la depuración estética (p. 109).

Las ideas planteadas por Shulman y Delgado nos permiten aseverar que los poetas modernistas peruanos tuvieron la necesidad de asimilar diversas tendencias con el fin de renovar y ensayar un lenguaje artístico a nivel de la forma y el contenido. Por tanto, el fenómeno literario del modernismo resulta complejo y heterogéneo; no existen fronteras rígidas, sino una flexibilidad en la asimilación de diferentes tendencias.

\section{Panorama del teatro peruano durante el modernismo}

En el Perú no hay un interés por determinar si el modernismo aportó o afloró en la composición teatral. La crítica no ha revisado los distintos discursos dramáticos de las primeras décadas del siglo XX, solo presentan una visión general del proceso teatral.

Una notable mirada acorde a los asuntos del teatro peruano lo realiza Estuardo Núñez en La literatura peruana en el siglo XX (1965). Avizora la permanencia del perfil costumbrista del siglo anterior con el drama romántico y la comedia costumbrista, siendo esta última la expresión "criollista" de mayor trascendencia. Lo revelador en este breve apartado constituye el reconocimiento de Núñez por el emprendimiento de una innovadora representación teatral denominado "teatro poético" o "teatro de ideas" (debido al empleo del lirismo) cuyo esfuerzo inicial estarían en Verdolaga de Valdelomar y en el intento de Holofernes (1931) de Ventura García Calderón: el teatro poético posee "el mérito de haber creado la inquietud por formas nuevas, de poca acción y nada escenificables, pero en todo caso mostrativas a nuevas posibilidades" (p. 63).

Un acercamiento a las composiciones dramáticas de aquella época lo realiza Ricardo Silva-Santisteban en el quinto volumen de la Antología general del teatro peruano (2002) en donde establece que el número de piezas teatrales aparecidas en el siglo XX fueron pocas a diferencia del siglo XIX a causa del bajo estímulo y las 
dificultades de la sociedad. El crítico emprende un sondeo refinado entre los cuales se erige la renovación del teatro costumbrista, con la representación social de Yerovi; la desconocida faceta de dramaturgo de López Albújar con Desolación, drama que incorpora los ecos del teatro simbolista; y la tragedia incompleta de Verdolaga (XIX).

En El teatro de vanguardia en el Perú (2008), Laurietz Seda y Rubén Quiroz consideran la presencia de una renovación de la escena teatral a partir de 1920, ya que los dramaturgos, hartos de las estéticas románticas, realistas y costumbristas, asimilan nuevas tendencias expresivas determinadas por las influencias vanguardistas de $\mathrm{Eu}-$ ropa, lo cual convertirán a los lectores y espectadores en entes activos capaces de descifrar las obras no convencionales (pp. 11-13). Los autores no consideran la influencia del modernismo en el teatro ni esbozan una idea de que el modernismo encaminó al teatro vanguardista, debido a la "falta de estudios críticos y de una historia cuidadosa y completa” de las actividades teatrales en los primeros años del siglo XX (p. 16). ${ }^{1}$

Podríamos determinar que el consenso crítico apunta a que las composiciones dramáticas, durante el modernismo presentan un lenguaje refinado, dirigido a un grupo elitista o sector letrado minoritario y no a un público de masas acostumbrado a lo costumbrista, lo romántico o al realismo naturalista. De ahí que el desinterés del público haya determinado el fracaso de las representaciones y el rechazo de las publicaciones. No obstante, la crítica ha evaluado el teatro sin tomar en cuenta la tendencia conflictiva del modernismo y sin comprender que la aplicación de esta tendencia en una pieza teatral fue tardía a comparación de los demás géneros literarios. En ese sentido, el modernismo no se estableció de inmediato al teatro como en la poesía o en la narrativa.

\section{Análisis teatral de Desolación ${ }^{2}$}

El 11 de enero de 1917, en La Prensa, Abraham Valdelomar (2001) publicó una lectura valorativa sobre Desolación, indicando que, con un tema local, en un tiempo no

1 El término vanguardia en el teatro debe considerarse también a las nuevas expresiones artísticas que resultan inclasificables e innovadoras en el estilo dramático y en la técnica escénica. Borja Ruiz (2012) denomina a las tendencias teatrales vanguardistas "que, en clara oposición al estatus teatral mayoritario, insuflaron nuevos valores éticos, estéticos o técnicos a la práctica del teatro" (p. 29). Las piezas teatrales construidas por nuestro poeta modernista, en un afán por renovar los valores artísticos, constituye una obra inusitada con una preocupación en el lenguaje poético y en la calidad dramática.

2 Para nuestro análisis, tomaremos la pieza dramática Desolación de Enrique López Albújar aparecida en el quinto volumen de la Antología General del Teatro Peruano. Según el editor, el texto se rige al original. El drama termina con la referencia del lugar y la fecha en que concluyó: "Lima, 8 de octubre de 1908”. Este dato nos permite aseverar que Desolación se forjó en la plenitud del modernismo peruano, y que el autor siguió corrigiendo la prosa de los diálogos hasta conseguir una calidad estilística adecuada. Además, podríamos añadir que el contexto literario en 1917 era favorable para la pieza teatral, pues la predilección del público por el ambiente provincial se iba incrementando. 
lejano, en una ciudad tropical azotada por la peste, "el espíritu fino y fuerte" del escritor ha colocado el "vago misterio", la "tragedia lacerante" y la "honda tristeza" (204).

Para Valdelomar, la obra de "rara belleza emocionante" no es vulgar por la "sencillez armoniosa" y, pese a las referencias simbolistas, la clasifica de "esencialmente criolla" debido a la cercanía con el "cuadro de costumbres" enfocado en la vida de provincia (204). Esta breve interpretación de El Conde de Lemos refleja los parámetros críticos de la época y evidencia la inserción de la temática provincial en la tradición teatral. Lamentablemente, la crítica no ha profundizado sobre esta incursión de Enríquez López Albújar en el campo teatral.

El análisis de Desolación que realizaremos pretende evidenciar el consciente proceder estilístico en el manejo técnico del teatro desde el espacio semiológico ${ }^{3}$ y la presencia del ritmo en los diálogos en prosa. ${ }^{4}$

Para iniciar nuestro análisis, es preciso detallar la fábula dramática: la peste yace en un pueblo de provincia. Manuel y Luis se encuentran consternados por la muerte de Julia, la hija de su amigo Juan. Ramírez, el médico, esperando que cierren el ataúd, traslada a otro recinto a los demás hijos del desdichado. Por su parte, el Inspector de Higiene intenta convencer a los curiosos a llevar el féretro al cementerio. Además, doña Rosario, la madre de Juan, quien no sabe de la muerte de su nieta, pretende ingresar a la casa, pero Manuel la retiene. Al término, mientras las personas llevan en hombros un ataúd, Juan, totalmente consternado, se despide del féretro y retorna a su hogar.

\subsection{Una tendencia experimental del espacio escenográfico}

La categoría del espacio dramático evidencia la especificidad donde se desarrolla el hecho teatral (las situaciones de la fábula y las posibilidades escénicas de los actantes) (Bobes Naves, p. 388). Las referencias textuales que tomaremos del "espacio

3 María del Carmen Bobes Naves en Semiología de la obra dramática (1997) ha desarrollado las categorías teatrales. Según Bobes Naves, el "Texto Dramático" es un producto histórico, cultural, artístico literario dispuesto a ser representado (84) y desentraña la alternancia simultánea de signos, tanto a nivel lingüístico del texto escrito como los signos no verbales del texto espectacular, que dan sentido a la pieza teatral. Este enfoque nos permite interpretar el sentido polivalente del texto literario dramático con categorías como la fábula, los personajes, el tiempo y el espacio (p. 286).

4 Los lineamientos de Isabel Paraíso de Leal en Teoría del ritmo de la prosa (1976) nos permiten verificar el ritmo de la prosa basado en la síntesis de la forma de la expresión y en la forma del contenido mediante tres categorías del ritmo dependiendo la tendencia rítmica, a saber: 1) el ritmo lingüístico, concerniente a la reiteración de las unidades lingüísticas estructuradas en líneas melódicas de entonación; 2) el ritmo tonal, generado por la reiteración de tensiones y distensiones orgánicas de uno o varios esquemas melódicos ascendentes y descendentes (el tonema ascendente anuncia una idea y mantiene la tensión, mientras que el tonema descendente satisface la espera para concluir la oración); y 3) el ritmo de pensamiento, constituido en la reiteración de elementos semánticos como la repetición de frases, palabras o esquemas sintácticos, y el paralelismo, motivado por representaciones psíquicas reiterativas . 
patente", visualizado en el escenario, y el "espacio latente", mencionado por las alusiones de los personajes, establecen el conocimiento de la dimensión escénica.

La pieza teatral, compuesta por ocho escenas, se desarrolla en un mismo espacio escenográfico. Al inicio de la obra, desde el plano de lo "patente" visualizamos el decorado del escenario:

Calle. Al fondo, una casa con la puerta principal abierta, dejando ver un patio. En éste atauid, un brasero y algo que simula un cadáver envuelto en una sábana. Gente que se mueve silenciosamente. Un individuo de rodillas preparando sus herramientas para soldar el ataúd. Al costado de la puerta, ventanas. La de la derecha del actor, abierta.

Estamos ante una concepción básica del teatro: el lugar de actuación se encuentra en el centro y de modo perpendicular al eje visual del público conocido como "Ámbito en T" (Bobes Naves, p. 392); sin embargo, este ámbito escénico adquiere una tendencia experimental al colocar dos espacios escenográficos: la calle, con un horizonte aparentemente desértico, sin mención de una naturaleza circundante; y la casa, al fondo, dejando a la vista "ventanas", una "puerta principal" abierta que permite ver un "patio" donde se encuentran un "ataúd", un "brasero", un "cadáver envuelto en una sábana", "gente" movilizándose y un "individuo" que se dispone a soldar el féretro.

La escasa descripción de la calle y del hogar revela el interés del autor por incrementar la especulación. Sin la necesidad de establecer una imagen aflictiva por medio de la palabra, los elementos de lo lúgubre en la disposición mínima de la escenografía, como el "ataúd” y el "cadáver envuelto en sábanas", producen un sentido integral de misterio que agobia al público y a los personajes.

La flexibilidad del ambiente escenográfico rompe con la concentración de un plano horizontal hacia dos planos escénicos. Esta preferencia constata la simpatía por determinar una representación realista, pues la interacción de dos niveles espaciales, en el escenario de "medio cajón", diversifica la atención del espectador para alcanzar una imagen similar a la vida de provincia: mientras los personajes se expresan en la calle, la diversidad de acotaciones y referencias en los diálogos sugieren diversos sucesos en las imaginarias habitaciones que compone el espacio interior de la casa.

Desde una mirada "latente", existe una dinámica de los espacios escenográficos. Las menciones de entrada por los laterales del camino, y las salidas e ingresos al hogar, conllevan a comprender el vínculo entre ambos espacios. Las acotaciones sugieren que la mayoría de los curiosos aparecen y salen por la calle ("Manuel, vecinos, Luis llegando por la izquierda", "Aparece por la derecha la madre de Juan”); el médico, el Inspector de Higiene y la Enfermera entran, salen y reingresan a la casa (" $R a$ mirez, el Inspector y la Enfermera entran"); el grupo de niños con la hija mayor de Juan ("Toman por la izquierda al llegar a la puerta", "Avanza el grupo por la izquierda 
y desaparece") y los cargadores del ataúd son los que salen del ambiente hogareño; mientras que Juan, en un acto de despedida al cadáver, antes del telón, es el único que sale y regresa a la casa.

Los ingresos y las salidas configuran un escenario dividido, el cual provoca un efecto visual de contraste. Amparándonos en las referencias "latentes" de los diálogos, el lugar más seguro constituye la calle, ya que el domicilio de Juan se ha convertido "en hospital". Pese a que el médico y el inspector ingresan, los curiosos $\mathrm{y}$ vecinos perciben el cuadro atroz desde lejos sin atreverse a ingresar por temor a ser contagiados (“¿Quién nos garantiza que no nos va a pasar nada?”); incluso la enfermera, temerosa por la infección, huye despavorida, olvidándose el compromiso de asistir a los pacientes ("yo no sigo más en esta casa”, “Tengo miedo!... ¡Miedo, doctor!"). Solo a doña Rosario, sin importarle la epidemia con tal de acompañar a su hijo, le impiden el ingreso.

Es posible determinar que el espacio abierto alude a una relación semiótica con la vida, mientras que el interior de la casa sugiere la presencia de la muerte. La oposición "dentro/fuera" de la casa concibe una radical intensificación de diversos sentidos: para Juan, "dentro" significa estar con la familia, asimilar la pena, y "fuera" es solo la despedida; para los "curiosos", "fuera" es estar a salvo de la peste, pero "dentro" los expone a la enfermedad. Además, la presencia o la ausencia de la peste será determinante en el comportamiento de los personajes: aquellos que están afuera no desean entrar y se ven aliviados por no estar contagiados, pero los que se encuentran dentro, o bien están consternados o bien huyen despavoridos.

Evidenciamos otros "espacios latentes" contiguos. Se señala el lugar extenso que constituyen la presencia de viviendas ("no quiere volver ni por los alrededores de la manzana"), la instalación reciente de un nuevo centro de salud ("condúzcales al pabellón del hospital nuevo") y el camposanto donde colocarán cerca al ataúd (“Detrás del cementerio, ¿̇no, señor?”). Estas breves alusiones a los lugares externos nos dan los rasgos característicos del espacio provincial en que se desarrollan las situaciones.

Desde este enfoque, López Albújar es consciente del uso de la tendencia realista del espacio con la finalidad de presentar los movimientos, los diálogos de los personajes de una manera verosímil, pero, al mismo tiempo, pretende inscribir un tono de misterio mediante sugerencias de situaciones tristes donde solo se visualizan movimientos retardados o alaridos. Las referencias "Adentro el cuadro debe ser atroz" o "¿Las consideraciones que sugiere este cuadro!", aluden una imagen terrible por lo que los personajes toman cierta distancia. Este alejamiento del lugar propicia una perspectiva en profundidad con la intención de intensificar la tensión del espectáculo, crear un ambiente desolador y, a la vez, fomentar la incertidumbre del público. 


\subsection{La fijación del tiempo dramático}

El diseño temporal de Desolación se edifica a partir de dos elementos textuales arquitectónicos: el tiempo estructural de la historia (el contexto de los personajes) y la linealidad del tiempo discursivo en base a las expresiones de la representación de la fábula.

Verificamos los sucesos previos a las situaciones del drama mediante las siguientes referencias: Luis manifiesta que hace diez días se celebró los quince años de Julia, hija de Juan, y que al día siguiente la niña cayó enferma de la peste. Luego, Luis asegura que en "menos de seis días" la casa se convirtió en un hospital; esta calamidad le recuerda que en la ciudad han ocurrido otros "cinco casos" similares. Por otra parte, Ramírez, el médico, comenta que hace "tres noches" no ha conciliado sueño, y Manuel anuncia que el día de ayer murió un hijo de Juan y que no hace una hora falleció Julia.

Respecto a la "duración" de las situaciones, se establece una temporalidad lineal de las escenas en un momento objetivo de la vida de los personajes. Las secuencias se registran en un lapso temporal del atardecer, si seguimos el dato de la $\mathrm{Hija} \mathrm{Ma}-$ yor que prefiere esperar la llegada de la noche para salir. Esta referencia podemos reforzarla cuando Luis menciona que "Todavía el sol mortifica".

Hemos evidenciado la presencia de dos espacios en un escenario, pero, durante la representación, los personajes de la calle dialogan mientras que los de la casa se mantienen en silencio o emiten algún quejido o alarido. Este efecto trae consigo la realización de un tiempo simultáneo de representatividad: a medida que los personajes enuncian los diálogos y cuentan los sucesos del interior de la casa, también se pueden visualizar movimientos o escuchar sonidos de los que se encuentran dentro. Un ejemplo es la conversación entre Manuel, Luis y Ramírez hasta que "Se oyen quejidos adentro": al escuchar ese sonido, Manuel se pregunta si “¿Han oído?”. Si bien este recurso de simultaneidad no crea problemas de percepción, sí enlaza un vínculo con los personajes: cualquier lamento modifica la compostura de los personajes.

Los simultáneos sucesos determinan el tiempo de la historia conformado desde hace una semana y centrado en un lapso temporal de un día. La referencia de cinco casos a consecuencia de la peste y la muerte de la hija de Juan presagia la perenne presencia de la peste que puede seguir azotando a la familia y a los pobladores de la ciudad. El marco temporal, entonces, presenta un orden acumulativo que acrecienta la tensión hacia el desenlace trágico de la muerte. Por ello, la obra termina con la aparición de todos los personajes contemplando la marcha fúnebre saliendo de la casa. El tema trágico de la peste evidencia poéticamente la angustia ante el acontecimiento desconocido con la intención de también desconcertar al público frente a una situación real de la fatalidad del hombre al enfrentarse a la fatalidad. 
López Albújar nos presenta un espacio imaginario en un tiempo regido por el estilo realista. Se procura que el marco temporal sea una reproducción del marco cronológico real, por lo que la obra presenta una zona limitada de un continuo vital que coincide con la extensión limitada del discurso.

\subsection{Los personajes dramáticos}

La lista de "Personajes" brinda datos mediante los nombres propios y comunes. Mientras las actitudes de Luis, Manuel, Ramírez, doña Rosario y Lucas se irán perfilando conforme se desenvuelven en los diálogos; la Hija Mayor, la Niña 2a, la Niña $3^{\mathrm{a}}$, el Inspector de Higiene, el Hombre $1^{\mathrm{o}}$, el Hombre $2^{\circ}$, la Mujer $1^{\mathrm{a}}$ y la Mujer 2a ${ }^{\text {a }}$ la Enfermera y los Cargadores, proporcionan una información denotativa de parentesco, de profesión o de referencia al pueblo con las referencias textuales y los rasgos funcionales.

Dentro del conjunto de personajes, no se colocan otros nombres propios a diferencia de los nombres comunes que aparecen en las acotaciones como Juan, los "vecinos" o "curiosos", la "Gente" dentro de la casa, "Tomás”, pariente de Juan, y las “mujeres del pueblo". Esta omisión, alude a que López Albújar no los considera como personajes propiamente dichos porque no se comunican o entablan diálogo con los demás.

Para comprender el dinamismo del pueblo imaginario de provincia trataremos de separar el grupo de personajes que intervienen mediante el diálogo, de los que se mantienen en silencio, pero participan en la representación mediante las acotaciones. De esta manera, podremos entender el sentido de los personajes motivados por sus características personales y las relaciones con los otros en una realidad devastada por la peste.

\section{a. Tendencia realista en los personajes}

Los personajes presentados con sus respectivos nombres, conforme a la tendencia realista, se confrontan ante la terrible situación de la peste, la cual convierte el lugar en un espacio hostil y desolador. Veamos, de manera sucinta, el comportamiento y las expresiones de las figuras teatrales durante el incremento y la disminución de la tensión.

La aparición de Luis y Manuel en la primera escena constituye el primer impacto emocional: el diálogo incide en la presencia de la peste en el pueblo (L: "Creo que son ya cinco los casos") y alude a las situaciones que podrían estar desarrollándose en la casa (L: "Adentro el cuadro debe ser atroz").

Ambos personajes exhiben la angustia de los pobladores y el desasosiego que padece Juan. Especulan que el desdichado podría considerar que vive una ironía, pues ve a la servidumbre con vida y contempla a sus hijos muertos. Según Luis, los 
pobres no pensarían de la misma manera ("El egoísmo es mal consejero"), ya que no sentirían felicidad con cualquier muerte. Menciona que la gente pobre, sin temor al contagio, se encuentra con ellos, demostrando la solidaridad ante al dolor ajeno.

En la segunda escena, aparece el doctor Ramírez "con botas y un estuche de cirujano", felicitando a Manuel y a Luis por la muestra de solidaridad. Las expresiones del médico contienen una postura profesional: aunque no ha dormido en tres días, su compromiso es asistir a los pacientes.

La desprendida labor de Ramírez, quien revela ciertos acontecimientos en la casa ("una grita, otra ríe, la de más allá forcejea y ruge como si le metieran un hierro en las entrañas"), se ve contrastada con la ausencia del médico titular, lo que genera la indignación de Manuel (M: "Es uno de los empecinados en no creer en la peste, y, sin embargo, no quiere volver ni por los alrededores de la manzana."). Al término de la escena, una voz lastimera convoca al Inspector de Higiene quien ingresa con Ramírez a la casa.

La tercera escena establece el segundo impacto de tensión con la primera salida de un grupo desde el interior de la casa. Los enunciados de cada personaje agudizan la congoja del escenario. La conmoción se asienta en las hijas de Juan: la Niña $2^{\text {a }}$ y la Niña 3a, que "Rompe a llorar", claman por su madre; mientras que la Hija Mayor consulta qué es lo que pasará con su madre y sus demás hermanas que aún yacen dentro. Al término, por órdenes de Ramírez, las tres son conducidas por Tomás (pariente de la familia) al nuevo hospital.

En la siguiente escena, el Inspector de Higiene realiza una petición a "dos hombres", que se encuentran acompañados por sus esposas, para sacar el cadáver por cuatro soles. El Hombre $1^{\circ}$ y el Hombre $2^{\circ}$ desisten en cargar en hombros el féretro por temor al contagio, incluso las mujeres les prohíben realizar dicho acto, pues sus hijos quedarían desamparados. En esta negativa, las expresiones de los pobladores evidencian las marcas discursivas del espacio imaginario regional: "si te da el contagio y te mueres, naides les va a dar pa comer a tus hijos", “No ves que es el ispetor!", "Como es usted dotor...".

El Inspector no comprende la falta de caridad y el pánico que perturba a los pueblerinos. Si bien no los obliga a sacar el féretro, la cólera por no conseguir una inmediata ayuda del pueblo o de las cuadrillas municipales de desinfección, lo conlleva a expresarse con agravios: “¡No seas bruto!”, “CCállese usted, señora!”, “Se calla usted, insolente?”, “'Vaya usted a convencer a esta gente!”.

La quinta escena instaura el tercer impacto de tensión: la salida intempestiva de la Enfermera desde el interior de la casa. Las nerviosas expresiones se conjugan con un estado de ánimo alterado por las circunstancias, al punto de solicitar retirarse al médico y al Inspector. En esta escena, las acotaciones amplían el comportamiento de la asustada Enfermera tras recibir un escupitajo de un paciente en la mejilla: 
"suplicando e intentando arrodillarse", "con castañeo de dientes", "Siento algo que me quema aquí... aquí", “¡Ay, yo me siento mala!... Tengo... mucho... mucho... frío...”, “Ay! ¡Qué crueles son!”

El Inspector y Ramírez intentan persuadir a la Enfermera. Para ellos no hay motivo para sentir pavor y la exhortan a permanecer en la casa por la investidura médica. Ante la supuesta crueldad de las autoridades de salud, Ramírez señala la potestad del Inspector, el cual dispone que la Enfermera no salga sin su permiso.

En la sexta escena, aparece la madre de Juan, doña Rosario, preguntando a Manuel y a Luis el estado de su hijo y su nieta. Ambos personajes deciden eludir la respuesta: Manuel, "Mirando hacia adentro con inquietud" y Luis, "también inquieto", aminoran la complicada situación y le sugieren que no entre a la casa para no incomodarí a las personas. Decidida a ingresar, doña Rosario señala que "Nunca puede estar demás la asistencia de una madre”, y "con voz suplicante" menciona “;Pobre hijo mío!... "¿Qué has hecho para merecer tanta desgracia!". Posiblemente, esta referencia de un suceso desconocido se vincule con el trágico presente de Juan.

En la séptima escena se establece la cuarta conmoción tensiva: aparecen de la casa tres hombres cargando el ataúd, mientras Juan se arrodilla bendiciéndolo. Esta representación produce un cambio de actitud en los curiosos: quienes se mantenían cerca y no quisieron ayudar, ahora deciden intervenir al ver tan desgarrador cuadro. Así, a pesar de que el Inspector anuncia que será recompensada cualquier alma caritativa, Lucas (ya no como Hombre $1^{\circ}$, sino con nombre propio, consolidando así su participación humanitaria) decide sin titubear asistir al conjunto fúnebre sin recibir nada a cambio.

En la última escena, doña Rosario le increpa a Manuel por no haberle dicho la verdad y al pretender hablar con su hijo, Manuel le cierra el paso. Por otro lado, uno de los Cargadores le pregunta al Inspector si llevará el ataúd detrás del cementerio. Este lo reafirma e indica que deben colocarlo "Bien hondo y bastante cal encima". Doña Rosario, al escuchar tal información, repite “ßBien hondo, bien hondo!”. Al final, Juan se despide del féretro y, sin ver a su madre, retorna a casa.

La construcción de los personajes no es minuciosa. Lo principal son los diálogos independientes de la acción, las alusiones sobre los sucesos de la historia y los sobresaltos frente a la peste. De esta manera, la presencia de choques de tensión oscilatorios refleja el propósito del autor por conmover al lector y hacerlo partícipe de los desoladores momentos.

\section{b. Un personaje alejado de la tendencia realista}

Los demás personajes, como los "vecinos" o "curiosos" que "se agolpan a la puerta", la "Gente que se mueve silenciosamente" dentro de la casa; "Tomás", "uno de los parientes de Juan, que ha estado entre los curiosos desde el principio del drama", las "mujeres del 
pueblo", incluso Juan, prescinden de la comunicación sin abandonar las dimensiones de su comportamiento. Cada funcionalidad participa en la imagen dramática del pueblo devastado por la peste.

Enfoquémonos en la construcción de Juan. De los individuos que se mencionan o no se encuentran en la lista principal, este personaje contribuye categóricamente a la realización de la pieza teatral. Es probable que al no colocarlo en la relación de "Personajes", el autor haya pretendido también dejar a la expectativa al lector ante un individuo que va a situarse progresivamente en el centro de discusión. Veamos mediante el diálogo y las acotaciones, la edificación de este misterioso personaje.

Durante el avance del drama, cada sujeto aporta diversos indicios sobre Juan: "Juan no se da cuenta de nada. Acabo de verle cruzar el patio, indeciso, como idiota", "Qué ironía más feroz para el padre que la de ver salvados a dos de su servidumbre mientras a sus hijos se los va llevando la muerte”, “iLo que pensará Juan!", "No teme a la peste y está ya vacunado", “¿Qué se le puede decir a un hombre en la situación de Juan?”, “¡Y él cómo está? ¿Lo han visto?”, “Pobre hijo mío!... ¡Qué has hecho para merecer tanta desgracia!... ¡Tan bueno, tan noble!”, “El pobre parece loco. ¿`Te fijaste? ¡Cómo mira! No conoce a nadie”, “Juan, Juan!... ¿Qué, no me oyes?”

Las distintas referencias sobre Juan nos permiten determinar lo siguiente: dueño de una hacienda, sufre la pérdida de dos hijos producto de la peste, con la posibilidad de que pueda también fallecer sus cuatro hijas y su esposa. Esta desdicha lo ha dejado consternado y prefiere mantenerse en casa. Al salir el ataúd, al término de la obra, y hacerse presente en la calle, Juan aparece totalmente abstraído y ajeno a los llamados o las miradas.

Si bien los diálogos construyen la figura de Juan, con datos discretos y discontinuos, sobre lo que podría pensar o hacer en el interior de la casa, así como las referencias directas al verlo en la calle, estas indicaciones son limitadas, no acceden con certeza al pensamiento o la tristeza de Juan. En otros términos, los personajes enuncian solo conjeturas al encontrarse imposibilitados en determinar la psique de Juan.

Veamos ahora al personaje desde el enfoque de las acotaciones que podríamos denominarlas "intersticiales", ya que explican el tipo de personaje elaborado por el autor (Bobes Naves 176). En la segunda escena, se describe lo siguiente: "Juan aparece en traje descuidado, sin cuello y con gorra, en actitud de un hombre entontecido. Mira a todas partes como buscando algo y desaparece". La acotación facilita la construcción imaginaria de un ser sin ánimos de vivir, totalmente abatido, aturdido y desorientado.

En la escena séptima encontramos lo siguiente: "Aparece el ataúd cargado por tres hombres y Juan. Una vez en la acera el grupo, Juan se arrodilla, se descubre y bendice el ataúd con dolorosa unción. Todo esto en el mayor recogimiento". Esta acotación explica la idea del espectáculo en el espacio escénico: se personaliza a un individuo abatido y cabizbajo en el preciso instante de la reverencia religiosa al féretro. 
La última acotación corresponde al cierre del drama. Antes del telón, encontramos la construcción de un texto productor de sentido: "Juan, que no se ha enterado de la presencia de su madre, al perderse el féretro, le hace un adiós con la diestra y se entra". A pesar de la escasa información, la acotación adquiere sentido: la concentración en el ataúd contribuye a reforzar la actitud de despedida. El movimiento resulta irrelevante ("se entra"), pero cobra interés la actitud de Juan ("le hace un adiós con la diestra”) que expresa la sombría separación y la resignación del trágico final.

Ni las manifestaciones externas ni por un proceso de introspección comprendemos a Juan, quien se convierte en el principal sujeto de acción funcional en la representación. En ningún momento balbucea o emite palabra alguna, solo se nos muestra, más que la apariencia física, los semblantes anímicos que varían desde el aturdimiento hacia la resignación.

Por tanto, las acotaciones generan sensaciones y movimientos incipientes. López Albújar abandona el diálogo para presentar un final desolador con un acto de adiós sin la necesidad de palabras. La presentación de un personaje desamparado produce en el público desconcierto, pues se aleja de los modelos vigentes del teatro tradicional y se acerca a una visión de la realidad más compleja propio del simbolismo. ${ }^{5}$

\subsection{Análisis del ritmo en la prosa del diálogo teatral}

Según Isabel Paraíso de Leal (1976), cada tipo de prosa contiene determinadas características rítmicas dependiendo de la forma de expresión y de contenido (p. 286). Los diálogos en el teatro evidencian teóricamente un manejo de la narrativa, pero rítmicamente pueden revelarse rasgos de la "prosa poética"; en otras palabras, la intención literaria nos coloca frente a una "prosa dialogada artística" según la clasificación de Isabel Paraíso. Para el análisis hemos seleccionado dos segmentos de dos escenas con el fin de evidenciar la labor artística de López Albújar en Desolación.

\section{a. Escena primera}

El primer segmento del diálogo teatral lo hemos extraído de la primera escena que nos impresionó por la finura prosística, sin identificar a priori un diseño rítmico. Evaluemos mediante el ritmo lingüístico (grupo acentual y fónico), el ritmo tonal y el ritmo de pensamiento la labor artística de nuestro escritor en el drama:

5 La presencia del simbolismo brinda un estatuto de trascendencia al mundo representado. Oliva y Torres (1990) señalan lo siguiente: "Entre las características más importantes del simbolismo podemos señalar la búsqueda de la Idea por el Hombre, por medio de la intuición y la meditación. No se tomará como modelo, como ha hecho el arte realista [...], la cosa en su objetividad externa. Hay que penetrar más en lo profundo. Hay que buscar en la mente, en el espíritu, a través de la cultura, de la mitología y de la historia, las ideas y las imágenes capaces de expresar al hombre en su totalidad" (290). En ese sentido, López Albújar profundiza el espíritu del personaje en su lejanía y en una realidad totalmente adversa. 
G.A.

3 LUIS: Adentro - el cuadro - debe ser atroz. $\searrow$

4 MANUEL: Juan - no - se da cuenta - de nada. $\searrow$

4 Acabo - de verle - cruzar - el patio, ^

1 indeciso, $\curvearrowright$

1 como idiota... \

2 LUIS: No es - para menos. $\downarrow$

3 MANUEL: ¡Las consideraciones - que sugiere - estecuadro! ${ }^{6} \searrow$

G.F.

Ver - su casa - convertida - en hospital - en menos de seis días. $\searrow$

LUIS: Creo - que son - ya cinco - los casos. \

MANUEL: Cinco. $\searrow$

LUIS: ¡Tan súbita - mente! \

MANUEL: Tan traidoramente, $\curvearrowright$

cuando todo - le sonreía - al pobre - Juan. \

¡Ayer no más - sin saber - lo que era - llorar - a un hijo - muerto! \

Y hoy - tendrá - que llorar - a dos. \

Parece que la muerte - ha llegado - a esta casa - furiosa - de desquite. $\searrow$

LUIS: Ha - comenzado - por la más - lozana: ^

la de los quince. $\searrow$

Desde un enfoque del ritmo lingüístico, hemos descompuesto en grupos fónicos y acentuales el texto elegido. Los grupos fónicos evidencian un fortísimo crescendo/decrescendo: 1-17-1. La masa oracional que yace en el centro, se compone por secciones sintácticas menores en la que se señala de manera punzante y directa la funesta situación de Juan. Rodeando dicha masa significativa, se inicia y termina con alusiones al desconocimiento de lo que sucede en el interior de la casa, a saber: "Adentro el cuadro debe ser atroz" y “iLas consideraciones que sugiere este cuadro!”.

Los grupos acentuales reflejan una repetición rítmica de crescendo/decrescendo con un carácter dialogado cortante y que se dirige hacia la cumbre cuantitativa casi al término de la masa enunciativa central:

3./4.4.1.1./2.5./5./4./1./2./1.4.5.4.5./4.1./3

Veamos la repartición de los grupos acentuales:

6 Isabel Paraíso (1976) coloca un principio de flexibilidad en los grupos de acento: señala que "algunas prosas imponen la anulación o disminución de ciertos acentos principales, que pasan a ser secundarios, mientras otros secundarios cobran relieve de principales" (48). En tal virtud, encontramos una desacentuación rítmica producida por la cercanía acentual en "ser" ("debe ser atroz"), "no" ("No es para menos), "toda" ("con toda la familia"), "todo" ("cuando todo le sonreía") "mente" ("Tan traidoramente") y "era" ("lo que era llorar"); mientras que hay una acentuación por la importancia semántica del texto en "no" ("Juan no se da cuenta"), "mente" ("Tan súbitamente") y "pobre" ("al pobre Juan"). 
$\left.\begin{array}{ll}\text { unimembres: } & 5 \\ \text { trimembres: } & 2 \\ \text { pentamembres: } & 4\end{array}\right] \quad$ impares: 11 bimembre: 27 tetramembres: 61 pares: 8

Hay una presencia mayor de grupos acentuales impares por sobre los grupos pares. Este dato nos permite establecer que el texto posee un carácter básico de sinceridad introspectiva y tono subjetivo, enlazado con el detalle de lo objetivo.

Los unimembres evidencian el trazo ligero del estilo directo y enfático, fragmentado por las comas o los dos puntos; mientras los trimembres, por su parte, recogen la solemne conmoción ("Adentro - el cuadro - debe ser atroz”, ““iLas consideraciones - que sugiere - este cuadro!"). En los grupos de cinco, se evidencian con claridad una prosa grandilocuente que concuerda con las circunstancias o las reflexiones de los personajes en plena atmósfera sombría ("Ver - su casa - convertida - en hospital - en menos de seis días", "Y con la perspectiva - aterradora - de que la peste - arrase - con toda la familia", " Ayer no más - sin saber - lo que era - llorar - a un hijo - muerto!", "Parece que la muerte - ha llegado - a esta casa furiosa - de desquite").

Por otra parte, los bimembres son los grupos de la brevedad y de las resoluciones ("No es - para menos”, “Tan súbita - mente!”), mientras los grupos largos de cuatro miembros recogen valores estilísticos y son usados para las comprobaciones resignadas y las descripciones melancólicas ("Juan - no - se da cuenta - de nada", "Acabo - de verle - cruzar - el patio", "Creo - que son - ya cinco - los casos", "cuando todo - le sonreía - al pobre - Juan", "Y hoy - tendrá - que llorar - a dos", "Ha - comenzado - por la más - lozana").

Desde la mirada del ritmo tonal, debemos exponer los resultados del análisis de los tonemas en el fragmento citado:

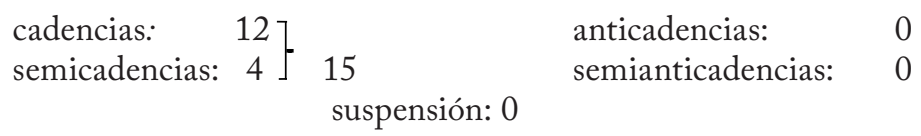

Los resultados confirman la presencia de una prosa dialogada. El texto se configura con un tono directo y solemne por el predominio categórico de los tonemas descendientes sin la presencia de tonemas graves.

Con respecto al ritmo de pensamiento, el texto revela la importancia de la prosa con el propósito de ofrecer un tono sentimental e individualista. La linearidad en Desolación se fortalece, pese a una ruptura temporal en la narración. Las referencias de los personajes sobre el ambiente triste se concentran en una mirada continua desde lo exterior. Sin embargo, encontramos ciertos elementos repetitivos que aumentan la expresión sonora del mensaje que se acerca a la prosa poética y a la retórica: 
a) Creo que son ya cinco los casos / Cinco // ¡Tan súbitamente! / Tan traidoramente, [anáfora paralelística y paralelismo sinonímico] ${ }^{7}$

b) ¡Ayer no más sin saber lo que era llorar a un hijo muerto! / Y hoy tendrá que llorar a dos [paralelismo antitético: en este segmento tiende a presenciarse la antilinearidad].

En esta labor del ritmo en los diálogos teatrales, evidenciamos una supremacía de formas narrativas breves propias de una prosa dialogada artística, pero que, en varias ocasiones, albergan rasgos de la prosa poética. No es casual que al inicio y al término de la pieza teatral encontremos ritmos de pensamiento regidos por la linearidad, por anáforas paralelísticas (sinonímicas) que impresionan al lector:

\section{ESCENA PRIMERA}

LUIS: No hará una hora. MANUEL: Va una
ESCENA ÚLTIMA

INSPECTOR: Bien hondo y bastante cal encima.

ROSARIO: ¡Bien bondo, bien bondo!...

El ritmo de tono registra una melodía repetitiva con altos índices de tonemas descendentes, dado la particularidad melancólica y reflexiva. Los ritmos lingüísticos, por su parte, predominan los grupos impares, sobre todo los unimembres, lo cual inducen una lectura pormenorizada semejante al tempo introspectivo en las situaciones conmovedoras. La presencia de grupos largos no es muy frecuente, pero que esporádicamente emergen por el tempo elocutivo que exigen momentos de circunstancialidad y cargada de significación estilística. Por tanto, el texto teatral desde el enfoque rítmico nos permite entrever una emoción refrenada, con atisbos de reflexiones y detalles objetivos, que determina la resignación de una realidad trágica y desoladora.

\section{Conclusiones}

El espíritu del artista modernista busca distanciarse de los enfoques del romanticismo, el costumbrismo y el realismo naturalista. Frente a un público acostumbrado a las puestas en escenas tradicionales, la conciencia estética influenciada por lo europeo renueva la subjetividad, las expresiones del lenguaje, pues toda expresión de arte debe poseer un valor artístico. La búsqueda de técnicas y los procedimientos literarios les permiten romper levemente con las técnicas conservadoras.

En la obra de López Albújar, superviven rasgos del realismo naturalismo, pero se descubre en el tema y la tensión dramática una sensibilidad modernista determinada por el simbolismo. Este rasgo nos permite determinar una predisposición por renovar tanto a nivel temático como en la capacidad del lenguaje musical.

7 Es preciso colocar también otros paralelismos sinonímicos que refuerzan el ritmo en la prosa dialogada artística en la primera escena: Seguramente tenía ya incubado el mal /Seguramente // Ironías de la vida, / Ironías feroces // ¿Para qué viven los que sirven / ¿Para qué viven los hijos de los pobres? 
Esta labor artística, no obstante, no fue improvisada ni posee una carencia de significado o de organización. El resultado de las metodologías nos conduce a determinar el conocimiento, la exigencia y la intención de contribuir en la estructura teatral, pues los elementos formales y expresivos están esmeradamente elaborados para una posible representación en el escenario.

El arte dramático en el texto literario y el texto dramático evidencian una síntesis de tendencias tradicionales y modernas, lo que otorga que en este periodo cultural posea un perfil diferente. El ánimo por modernizar el discurso dramático se ajustó a las normas imperantes de la época, sea para el gusto del público o para conseguir la puesta en escena.

En Desolación se asimilan los rasgos del realismo naturalismo, la tensión y sensibilidad del simbolista, variante del modernismo. El tono lúgubre y la constante disposición del misterio alcanzan su mayor logro en toda la representación. Asimismo, la prosa dialogada demuestra índices de una melodía reflexiva y melódica que, en breves instancias, contienen una emoción refrenada con breves rasgos de prosa poética.

La presencia del modernismo en el teatro peruano, por tanto, reconfigura, renueva y diseña sus propias características por medio del contenido y el ritmo. Examinar esta pieza dramática producida en el periodo del modernismo peruano nos permite comprender la formación del teatro peruano en los primeros años del siglo XX.

\section{Referencias}

\section{Primaria}

López Albújar, Enrique. (2002). Desolación. En Antología general del teatro peruano. Tomo V: Teatro republicano - Siglo XX-1. Selección, prólogo y bibliografía de Ricardo Silva-Santisteban. (pp. 82-106). Lima: Banco Continental - Pontificia Universidad Católica del Perú.

- (1963). Memorias. Prólogo de Ciro Alegría. Colofón y Bibliografía de Raúl-Estuardo Cornejo. Lima: Talleres Gráficos P.L. Villanueva, 1963.

\section{Secundaria}

Aristóteles. (2000). Poética. Traducción, introducción y notas de Salvador Mas. Madrid: Biblioteca Nueva.

Balta Campbell, Aída. (2001). Historia General del teatro en el Perú. Lima: Universidad de San Martín de Porres.

Bobes Naves, María del Carmen. (1997). Semiología de la obra dramática. Madrid: Arco/ Libros.

Dauster, Frank. (1973). Historia del teatro hispanoamericano. México: Andrea.

Delgado, Washington. (1980). Historia de la literatura republicana. Lima: Rikchay Perú. 
García-Bedoya, Carlos. (2004). Para una periodización de la literatura peruana. 2da. Ed. corregida y aumentada. Lima: Fondo Editorial de la UNMSM.

Henríquez Ureña, Max. Breve historia del Modernismo. México: Fondo de Cultura Económica, 1978.

Henríquez Ureña, Pedro. (1964). Las Corrientes Literarias en la América Hispánica. 3ra. Ed. México: Fondo de Cultura Económica.

Hernández, José A. (1950). “Notas sobre teatro peruano contemporáneo”, en Mar del Sur: Revista Peruana de Cultura. Vol. IV, No 10, marzo-abril. (pp. 161-171). Lima: P. L. Villanueva.

Hesse Murga, José. (1963). "El teatro en el Perú”. Prólogo. En Teatro peruano contemporáneo. 2da. Ed. (pp. 9-26). Madrid, Aguilar.

Le Corre, Hervé. (2001). Poesía hispanoamericana posmodernista. Historia, teoría, prácticas. Madrid: Gredos.

Navarro Tomás, Tomás. (1972). Métrica española. Reseña bistórica y descriptiva. Madrid: Guadarrama.

Núñez, Estuardo. (1965). "El teatro". En La literatura peruana en el siglo XX. (pp. 6070). México: Pormaca.

Paraíso De Leal, Isabel. (1976). Teoría del ritmo de la prosa. Barcelona: Planeta.

Rama, Ángel. (1970). Rubén Dario y el modernismo: circunstancia socio-económica de un arte americano. Caracas: Universidad Central de Venezuela.

Reverte Bernal, Concepción. (2006). Teatro y Vanguardia en Hispanoamérica. Madrid: Iberoamericana.

Risk, Beatriz J. (1987). “Antecedentes de Nuevo teatro en la América Latina”. En El Nuevo Teatro Latinoamericano: una lectura histórica. (pp. 85-136). Minneapolis: Prisma Institute and Study of Ideologies and Literature.

Rivera Saavedra, Juan. (2007). Apuntes para una historia del teatro peruano. Lima: Fondo Editorial de la Universidad Alas Peruanas.

Ruiz, Borja. (2012). El Arte del Actor en el siglo XX. Un recorrido teórico y práctico por las vanguardias. 2a ed. Bilbao: Editorial Artezblai.

Schulman, Ivan A. (1969). El modernismo hispanoamericano. Buenos Aires: Centro Editor de América Latina.

Seda, Laurietz y Rubén Quiroz (eds.).(2008). Travesías trifontes. El teatro de vanguardia en el Perú. Lima: Fondo Editorial de la UNMSM.

Silva-Santisteban, Ricardo (Selección, prólogo y bibliografía). (2002). Antología general del teatro peruano. Tomo V: Teatro republicano - Siglo XX-1. Lima: Banco Continental - Pontificia Universidad Católica del Perú.

Solórzano, Carlos. (1961). Teatro latinoamericano del siglo XX. Buenos Aires: Nueva Visión.

Valdelomar, Abraham. (2001). "Desolación. Drama en un acto de Enrique López Albújar”. En sus Obras completas IV. (pp. 204-206). Lima: Ediciones Copé. 